\title{
Expressões estéticas contemporâneas de resistência da juventude urbana e a luta por reconhecimento uma leitura a partir de Nietzsche e Axel
Honneth
}

Mônica G. T. do Amaral ${ }^{1}$

Resumo

$\mathrm{O}$ artigo propõe um debate a partir das proposições de Nietzsche sobre a genealogia da moral e de suas ideias sobre a moral nobre e a moral do escravo, a moral de rebanho e o espírito livre, tomando esse conjunto de proposições como ferramenta de leitura de algumas letras de rap. Ao mesmo tempo, inspirado por um trabalho de pesquisa em educação com o rap na periferia, pretende provocar novas tensões nas ideias deste pensador, refletindo particularmente sobre as condições que têm sido enfrentadas pelas populações historicamente prejudicadas em nossa sociedade, por meio da leitura da gramática moral do conflito proposta por Axel Honneth.

\section{Palavras-chave}

A moral de rebanho e o espírito livre, a moral nobre e o rap, o reconhecimento recusado e a humilhação social, a territorialidade libertária e a identidade afirmativa.

Recebido em 4 de fevereiro de 2013

Aprovado em 14 de março de 2013

AMARAL, Mônica G. T.. Expressões estéticas contemporâneas de resistência da juventude urbana e a luta por reconhecimento: uma leitura a partir de Nietzsche e Axel Honneth. Revista do Instituto de Estudos Brasileiros, Brasil, n. 56, p. 73-100, jun. 2013. D0I: http://dx.doi.org/10.11606/issn.2316-901X.v0i56p73-100

1 Universidade de São Paulo (USP, São Paulo, SP, Brasil). 


\section{Contemporary Aesthetical Expressions of Resistance by the Urban Youth and the Struggle for Recognition a Reading of Nietzsche and Axel Honneth}

Mônica G. T. do Amaral

Abstract

The article proposes a debate based on Nietzsche's propositions about the genealogy of morals and his ideas about the master and the slave morality, the herd morality and the free spirit, by taking all these tools to approach some rap lyrics. At the same time, inspired by a field research about education through rap in the outskirts, we intend to provoke new tensions in this thinker's ideas, particularly by reflecting on the conditions that populations historically harmed in our society have been facing, with the understanding of the moral grammar of conflicts as proposed by Axel Honneth.

Key words

herd morality and free spirit, master morality and rap, the recognition neglected and social humiliation, libertarian territory and affirmative identity. 
Onde um homem chega à convicção fundamental de que é preciso que mandem nele, ele se torna "crente"; inversamente, seria possível um prazer e força de autodeterminação, uma liberdade da vontade, em que um espírito se despede de toda crença, de todo desejo de certeza, exercitado, como ele está, em poder manter-se em leves cordas e possibilidades, e mesmo diante de abismos dançar ainda. Um tal espírito seria o espírito livre par excellence . ${ }^{2}$

2 NIETZSCHE, Friedrich. A gaiaciência. In: Os Pensadores. Obras Incompletas. Seleção de textos de Gerard Lebrun. $z^{\mathrm{a}}$ ed. São Paulo: Abril Cultural, 198za. Aforismo 347, p. 215 . 


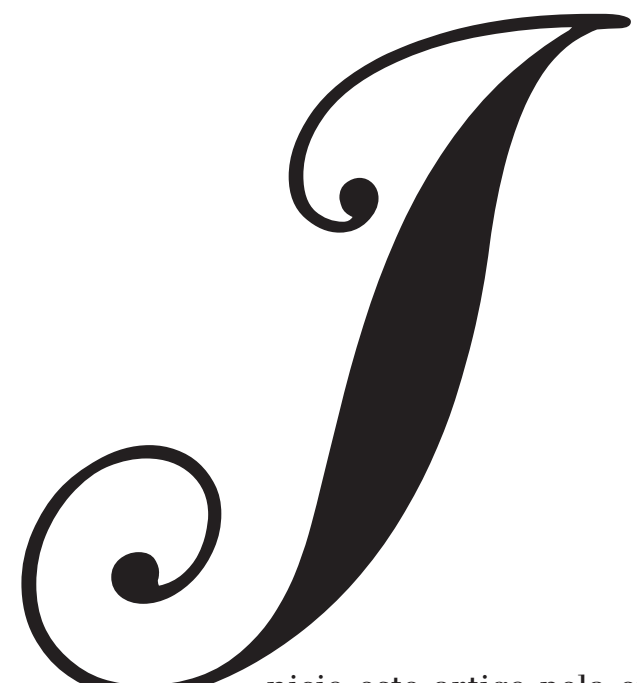

nicio este artigo pela epígrafe acima de Nietzsche para pensar em que bases se construiu a Razão Ocidental, cujo poder de esclarecimento há muito se esgotou e deu origem ao monoculturalismo e à hegemonia cultural eurocêntrica e posteriormente, estadunidense ${ }^{3}$ verificada com a expansão da indústria cultural americana pelo mundo - assim como à exploração socioeconômica no pós-colonialismo.

O que se entende por "espírito livre"? De acordo com o filósofo alemão, seria atribuído a todo aquele que se libertasse das amarras da coletividade, do pensamento "rebanho" e expressasse a singularidade de seu ser. Giacoia ${ }^{4}$ sustenta que os espíritos muito livres, os filósofos do futuro, permanecerão "amantes da verdade" (fiéis à filosofia), e necessitariam de uma "nova atmosfera espiritual" que somente o "aprofundamento do

3 Rodrigo Duarte em seu artigo, "Indústria cultural hoje", sustenta que a grande mudança em relação a setenta anos atrás, quando pela primeira vez foi mencionado o termo indústria cultural pelos filósofos Theodor Adorno e Max Horkheimer, (Dialética do esclarecimento - 1947. Trad. Guido Antonio de Almeida. Rio de Janeiro: Zahar, 1985, p. 113-156) é que houve um novo avanço no processo de mundialização entre os anos 1980 e 1990, consolidada com o fim do bloco soviético, que tornou a ideia de Mc Luhan de "aldeia global” realidade efetiva. No entanto, ao contrário do que previu o filósofo canadense, a globalização dos meios de comunicação não se deu de forma recíproca. Basta observar a crescente estadunização particularmente dos programas televisivos em todo o mundo, atingindo em grande parte a Europa (em 1991, atingia cerca de $30 \%$, chegando na Alemanha a 67\%). Dentre os países menos desenvolvidos da Ásia e da América Latina, o índice era muito maior. In: DURÃ̃, F. A.; ZUIN, A. A. S.; VAZ, A. F. (Orgs.). A indústria cultural hoje. São Paulo: Boitempo, 2008, p. 97-110).

4. GIACOIA JÚNIOR, Oswaldo. Nietzsche \& Para além de bem e mal. 2. ed. Rio de Janeiro: Jorge Zahar, 2005, p. 33. 
programa do esclarecimento" tornaria possível. Mas não seriam dogmáticos, como se pode verificar no Aforismo 43 de Além do bem e do mal:

Ofenderia seu orgulho, e também seu gosto, se a sua verdade fosse tida como verdade para todos: o que sempre foi, até hoje, desejo e sentido oculto de todas as aspirações dogmáticas [...]. É preciso livrar-se do mau gosto de querer estar de acordo com muitos. ${ }^{5}$

Scarlett Marton ${ }^{6}$ considera que muitos dos impasses preconizados por Nietzsche com o advento da modernidade remetem necessariamente à crise da tradição socrático-platônica, presente no cristianismo e em todas as formas de secularização modernas, cujos ídolos - o Estado, as instituições, a moral, as ilusões da filosofia, a verdade - Nietzsche teria pretendido destruir a "marteladas". Martelo que pode ser compreendido como "marreta", mas também como "diapasão" para diagnosticar o seu vazio, segundo Paulo César de Souza ${ }^{7}$, ou seja, o declínio de todos os valores sustentados até então. Segundo Giacoia ${ }^{8}$, Nietzsche visualiza um novo homem, capaz de "tomar o martelo e o cinzel para esculpir a figura do futuro humano na história. Esse é o assustador limiar de autodeterminação em que se coloca a modernidade". E o niilismo, resultante do processo de desvalorização de todos os valores em curso da modernidade, a partir do qual Nietzsche defende como antídoto a ideia de "estética extrema", apoiada em afecções fortes, de onde se promoveria a "transvaloração de todos os valores". São ideias identificadas por Heidegger ${ }^{9}$, particularmente desde o Crepúsculo dos ídolos ${ }^{10}$.

$\mathrm{Na}$ esteira dessas ideias, eu me pergunto a propósito do mundo contemporâneo: Quem seria hoje porta-voz do "espírito livre", que de posse dessa marreta/diapasão diagnosticaria o vazio de nossa sociedade? E ainda, seria capaz de afirmar o negado por essa mesma sociedade e

5 NIETZSCHE, Friedrich. Além do bem e do mal: prelúdio a uma filosofia do futuro (1885/1886). Tradução, notas e posfácio de Paulo César de Souza. São Paulo: Companhia das Letras, 2005, p. 44.

6 MARTON, Scarlet. O homem que foi um campo de batalha. In: NIETZSCHE, Friedrich. O anticristo. Trad. de Noéli Correia de Melo. São Paulo: Martin Claret, 2005, p.11-19.

7 SOUZA, Paulo César de. Posfácio. In: NIETZSCHE, Friedrich. Crepúsculo dos ídolos. São Paulo: Companhia da Letras, 2006, p. 139-14,1.

8 GIACOIA JÚNIOR, Oswaldo. Nietzsche \& Para além de bem e mal, op. cit., p. 51.

9 HEIDEGGER, M. Nietzsche. Trad. Marco Antonio Casanova. Rio de Janeiro: Forense Universitária, v. 1, 2007.

10 NIETZSCHE, Friedrich. Crepúsculo dos ídolos (1888). Tradução, notas e posfácio de Paulo César de Souza, op. cit. 
romper as amarras territoriais e urbanas, identitárias e étnicas, sociais e culturais, fazendo emergir as vozes abafadas da juventude periférica de todo o mundo na era global?

Tenho sustentado, com base em nossas pesquisas sobre o hip hop ${ }^{11}$, que justamente os rappers, com sua crítica ousada e "estridente" dirigida ao mundo estabelecido global e excludente, sejam, não apenas os "novos cronistas da modernidade", como sustentara Contier ${ }^{12}$, mas os "novos críticos niilistas" do mundo contemporâneo, uma vez que não acreditam mais nos valores que sustentam nossas instituições e muito menos naqueles que alimentam a velha instituição escolar, com suas concepções, muitas vezes, ultrapassadas do que seja conhecimento "sério, erudito e/ou científico".

Scarlett ${ }^{13}$ relembra-nos que Lebrun, por sua vez, que fora responsável pela formação de toda uma geração de filósofos no Brasil, sustentara que não se devia interpretar as ideias de Nietzsche como se fosse um sistema filosófico a ser decifrado, mas sim considerá-lo "um instrumento de trabalho insubstituível" de leitura de mundo, e por isso, seria importante muito mais "pensar com ele".

Acredito que esta tem sido a orientação de nossas pesquisas: pensar um fenômeno atual como o hip hop em companhia das reflexões de Nietzsche ${ }^{14}$, ou conectá-los com esses fenômenos da cultura juvenil contemporânea, por meio dos quais faríamos passar o seu pensamento, procurando assim elucidar o modo como os mesmos incitam, à semelhança do que propusera esse pensador, "a transvaloração dos valores" vigentes em nossa sociedade. Ao que acrescentaria: sobretudo frente a um mundo incapaz de admitir a heterogeneidade, que tendeu a se acentuar com a política pós-colonial predominantemente diaspórica.

11 Refiro-me particularmente à pesquisa, sob o título Rappers, os novos mensageiros urbanos na periferia de São Paulo: a contestação estético-musical que emancipa e educa, op. cit.

12 CONTIER, A. D. (2005). O rap brasileiro e os Racionais MC's. Iniciado em 2011: Anais I Simpósio Internacional do Adolescente. São Paulo: Faculdade de Educação da Universidade de São Paulo. Disponível em: http://www.proceedings.scielo. br/scielo.php?script=sci_arttext\&pid=MSC0000000082005000100010\&lng $=\mathrm{en} \& \mathrm{nr}$ $\mathrm{m}=$ iso. Acesso em: mar. 2013.

13 MARTON, Scarlet. Pontos de inflexão acerca da recepção de Nietzsche na Itália. In: (Org.). Nietzsche pensador mediterrâneo: a recepção italiana. São Paulo:

Discurso/Ijuí: Unijuí, 2007, p. 13-68.

14. Refiro-me à minha tese de Livre-docência, A trama e a urdidura entre as culturas juvenis e a cultura escolar: a "eróptica" como método de pesquisa e de ruptura de campo. 2009. 338 f. Tese (Livre-docência) - Faculdade de Educação, Universidade de São Paulo, 20og. 
Desta vez, proponho-me a articular ao debate ensejado por Nietzsche para pensar questões contemporâneas relativas à nossa cultura - cujos valores têm sido denunciados pelos rappers por meio de uma crítica cortante - outro ângulo da discussão filosófica, introduzida por Axel Honneth $^{15}$. Este, tendo sido assistente de Habermas, traz uma contribuição no sentido de fazer avançar o debate sobre a razão instrumental denunciada pelos frankfurtianos e até mesmo de ação social tal como proposta por Habermas, admitindo, entretanto, o conflito social como central para repensá-la e cuja gramática moral é a "luta por reconhecimento".

Embora seja possível depreender das denúncias de rappers, como os Racionais MC's e Z'África Brasil, dentre outros, uma ruptura quase que total com a moralidade vigente, bem como com os valores que a sustentam, aproximando-se das posições niilistas de Nietzsche, pareceu-me útil recorrer ao debate sobre a "luta por reconhecimento", tal como propõe Honneth ${ }^{16}$, cujas formulações teóricas pressupõem, como veremos, uma confiança ainda que paradoxal no poder de esclarecimento da Razão, ideia presente na tradição filosófica frankfurtiana.

\section{Uma cena comum na periferia}

Uma brecada brusca...

Dois tiros, o barulho de uma moto em fuga... um cachorro latindo e um galo cantando...

Depois, ouve-se o despertador tocar, após o qual, somos apresentados à rádio Êxodus. Ao som do piano, ouvimos: "Bença, Mãe! Estamos iniciando nossas transmissões... Essa é a sua rádio, Êxodus, Hei! Hei!".

Em seguida, ergue-se a voz providencial de Mano Brown: "Vamo acordá, vamo acordá...”.

O sol não espera, demorô... o tempo não cansa...

Ontem à noite você pediu, uma oportunidade, mais uma chance... Como Deus é bom, não é não, nego? Mais um dia todo seu... céu azul loko, hem?

"Vamo acordá, vamo acordá..."

15 HONNETH, Axel. Luta por reconhecimento: a gramática moral dos conflitos sociais. Trad. Luiz Repa. São Paulo: Editora 34, 2003.

16 Idem, Ibidem. 
Agora vem com a sua cara

Sou mais você nessa guerra...

A premissa é inimiga da vitória, o fraco não tem espaço, e o covarde morre sem tentar...

Não vou te enganar... O bagulho tá doido, ninguém confia em ninguém, nem em você... Os inimigo vêm de graça... é a selva de pedra... eles matam os humildes demais

Você é do tamanho do seu sonho

Faz o certo, faz a sua...

"Vamo acordá, vamo acordá..."

Cabeça erguida, olhar sincero

Tá com medo de quê?

Nunca foi fácil, junta os seus pedaços e desce pra arena

Mas lembre-se: Aconteça o que aconteça, nada como um dia após outro dia...

(Racionais MC's. "Sou + você". Chora agora, ri depois (2006), relançado em 2011)

Iniciam-se as batidas de rap e o grupo anuncia: "É nóis mesmo vagabundo!".

E assim somos jogados no "coração da ação" dos "periféricos" de São Paulo, em meio à "selva de pedra" descrita na primeira letra do CD dos Racionais MC's - Chora agora, ri depois - onde se equilibram, no limiar entre a vida e a morte, centenas de jovens pobres, na sua maioria negros, em meio à guerra que se instaurou entre a polícia e os traficantes, dando lugar a chacinas que há muito vêm abalando a periferia desde os anos $1980^{17}$, incansavelmente denunciadas pelos rappers. Não se pode esquecer da quantidade de homicídios cometidos contra jovens moradores da periferia de São Paulo, envolvendo, dentre eles, rappers, como DJ Lah ${ }^{18}$,

17 Em uma oficina realizada com os jovens na ONG CZ, um de nossos pesquisadores, Djalma Leite, ao apresentar "Pânico na Zona Sul”, uma música dos Racionais MC's, esclareceu-nos que a letra trazia em seus versos o pânico relacionado à presença de matadores de aluguel na Zona Sul da cidade de São Paulo. Comentou sobre a história do Cabo Bruno, policial que, nos anos 1980, liderou um grupo de extermínio em bairros periféricos da cidade.

18 No início de dezembro, assistimos à substituição do secretário de Segurança Pública de São Paulo, tendo sido empossado Fernando Grella Vieira. Este assumiu a direção do órgão dizendo considerar inaceitável a taxa paulista de letalidade poli- 
em cujas músicas vinha denunciando a violência da polícia; ou mesmo daqueles que ousaram filmar a execução de um jovem dentro do carro da PM - cenário tenebroso em São Paulo que se estende desde outubro de 2011, como parte de um acerto de contas entre o PCC e a polícia militar da cidade.

No trecho acima da letra dos Racionais MC's, em ritmo de “canto falado" - uma marca do estilo musical assumido pelo rap - evidencia-se como esses músicos fazem para alertar o jovem negro ${ }^{19}$ e pobre, morador da periferia, sobre a importância da vida nesse cenário devastador. Ao mesmo tempo em que denunciam nada existir para protegê-lo, a não ser a consciência de que tem o direito de permanecer vivo e sonhar, deslocanos a todos, do centro para a periferia. Promove verdadeiros "atos de linguagem" 20 , ao empregar todos os recursos sonoros necessários para retratar a violência e os abusos da polícia que grassam na periferia.

Segundo Béthune ${ }^{21}$, “o rapper não fala da realidade, ele fala $n a$ realidade e, colocando-se no coração da ação, ele transforma fortemente sua fisionomia". É com tal realismo que tudo isso ocorre, que, muitas vezes, suas músicas são confundidas com uma verdadeira incitação à violência e ao crime. Mas é a revolução que nos espera... No ano passado, Mano Brown em seu clipe sobre o Marighella fez uma verdadeira convocação revolucionária da periferia, como estratégia de fazer ouvir esses jovens que vêm sendo sumariamente exterminados ${ }^{22}$.

cial: 447 pessoas morreram supostamente em tiroteio com PMs de outubro de 2011 a setembro de 2012 (Em entrevista concedida ao jornal O Estado de S. Paulo, caderno “Metrópole”, C1, 8 dez. 2012). Só em 2012, foram registradas 24 chacinas em São Paulo. No entanto, um mês depois, foi noticiada outra chacina, a qual suspeita-se ter sido cometida pela polícia. Dentre eles, encontrava-se o DJ Lah, admirado por seu trabalho com crianças e jovens da periferia da Zona Sul de São Paulo. Em seu enterro estiveram Mano Brown, considerado "pai” de uma geração significativa de rappers, e um dos principais escritores da periferia paulistana, Reginaldo Ferreira da Silva, Férrez, autor de Capão pecado. Este sustentou que na Zona Sul, região mais atingida por esses assassinatos, a população estava no "limite da opressão". "Estamos em uma ditadura, no limite da opressão. Nos bairros ricos, a polícia dá bom dia, dá boa tarde. Aqui, ela mata”, disse no velório.

19 É preciso salientar que uma pesquisa nacional sobre a violência realizada por Júlio Jacobo Waiselfsz, publicada no livro Mapa da violência (2011), constatou que, em 2008, por exemplo, a violência, resultando em morte, atingiu 103\% mais negros do que brancos. Embora esta diferença já existisse, há dez anos, era de $20 \%$.

20 Trata-se de um termo empregado por Christian Béthune (Le Rap: une esthétique hors de la loi. Paris: Autrement, 200z) para se referir ao caráter mimético e dramático da linguagem empregada pelos rappers.

21 BÉTHUNE, Christian. Le Rap: une esthétique hors de la loi, op. cit.

22 Em nosso trabalho de oficinas de rap oferecidas aos jovens do Capão Redondo, na ONG CZ, apresentamos o clipe de autoria de Mano Brown, Marighella (2012), para provocar uma discussão sobre as possíveis relações entre as lutas empreendidas 
Em seguida ao trecho da música mencionado acima, uma voz rouca e irônica de uma "criança sarcástica", acompanhada das batidas de rap e de um coro de mulheres, estilo gospel, deixa claro a quem se dirige a mensagem da rádio Êxodus:

Você está nas ruas de São Paulo, onde o vagabundo guarda o sentimento na solo do pé. Não é pessimismo, não, é assim que é... É doce veneno... Viajei e voltei pra você... Votei pelos loko, votei pelos pretos, pelas verde, consequentemente.

Entre um tom jocoso e sonhador, faz um "salve" aos avanços da sociedade tecnológica:

Ei, você sonhador que ainda acredita...Viva nóis... Eu tenho fé e amor no século XXI, onde as conquistas, científica, espaciais, medicinais e a confraternização dos homens e a humildade de um rei serão as armas da vitória para a paz universal...

$\mathrm{Ou}$ seja, se quisermos sobreviver como cidade, sociedade e civilização, é preciso voltar nossa atenção para essas populações historicamente excluídas e mais, que estão nas mãos de um Estado e polícia cuja ação conjugada tem sido pautada pela violência e arbitrariedade. E mesmo assim, é preciso manter a "esperança de uma paz universal". No clipe há pouco mencionado, Mano Brown se apresenta como o novo Marighella da periferia, que luta pelo reconhecimento da juventude excluída de nosso país e ultimamente, ao direito à vida, nem que para isso sejam necessárias as armas.

\section{Como é possível pensar o rap com Nietzsche}

Em contraposição à moral "socrático-platônica-cristã”, segundo Giacoia ${ }^{23}$, para o filósofo alemão, não existe a moral, mas inúmeras modalidades de moral. Ideia defendida por ele em sua própria tentativa de construir uma tipologia da moral, com as designações de moral dos senhores e de escravos, dos fortes e de rebanho. Referindo-se à obra

por lideranças revolucionárias no passado e o papel exercido pelos rappers hoje na periferia. No clipe, o rapper recorre à imagem histórica do guerrilheiro que lutou contra a ditadura de Vargas e depois contra a ditadura militar, para convocar os jovens negros da periferia ao levante, como fizera o líder revolucionário no passado. 
Além do bem e do mal, o autor reconhece que Nietzsche combina as perspectivas, histórica e psicológica, e detecta diferentes moralidades, resultantes de momentos distintos de cristalização de tais perspectivas.

É preciso atentar para o modo pelo qual se expressa a crítica nietzschiana, entre um tom jocoso, irônico e estridente, que, como salienta Giacoia $^{24}$, foi a forma encontrada pelo filósofo de radicalizar sua crítica à crença iluminista em qualquer forma de progresso ou de acesso à verdade pelo esclarecimento ou iluminação da consciência. No entanto, a paz e a felicidade alcançadas se daria segundo a perspectiva da moral de rebanho: "do bem estar, do conforto, da ausência de riscos, de perigos, de extremos"25.

Ao analisar o tom sarcástico e áspero adotado pelos Racionais MC's para se referir aos avanços tecnológicos, logo depois de sermos jogados no meio de um cenário em que a vida é o limite perante a iminência da "morte anunciada" dos jovens periféricos, evidencia-se quão atual é a crítica de Nietzsche à crença iluminista no progresso tecnológico, bem como no poder de esclarecimento da consciência. E de como se faz necessário o recurso à ironia e a expressões "estridentes" como "moral de rebanho" para "acordar" a sociedade. Mano Brown faz uso desde os ruídos da periferia, até de uma convocação performática, em estilo “canto falado", para "acordar" tanto o jovem em perigo, quanto todos os demais que vivem a "paz e a felicidade" das regiões privilegiadas da cidade, permeada pelo conforto e a ausência de riscos. O que o coloca na vanguarda da música produzida na contemporaneidade ${ }^{26}$.

As imagens de forte e fraco, senhor e escravo a que recorre Nietzsche ao longo de sua obra seguem na contramão das ideias modernas e por isso,

24. GIACOIA JÚNIOR., Oswaldo. 5 Lições sobre Nietzsche. Site da Area Sociedade $e$ Cultura. Disponível em: http://www.cefetsp.br/edu/eso/filosofia/aulanietzs-chegiacoiar.html. Acesso em: mar. 2013 .

25 Idem, Ibidem, I $^{\mathrm{a}}$ Lição, p.1z.

26 A esse respeito, há todo um debate que é retomado por Wisnik, em seu livro $O$ some o sentido (2007), em que nos adverte que, em todo caso, toda música estará sempre dialogando "com o ruído, a instabilidade, a dissonância". A música contemporânea, aliás, segundo o autor, torna bastante tênue o limiar entre som e ruído, ao contrário do que concebiam portugueses e brasileiros na época colonial e ainda hoje pensam aqueles que têm uma escuta voltada apenas para uma determinada tradição ocidental da música considerada erudita. $\mathrm{O}$ autor explicita que na música contemporânea há dois níveis diferenciados de manifestação do ruído: "a própria textura interna à linguagem musical, e a eclosão espetacular de ruidismos externos, como índices do habitat urbano-industrial, a metrópole chocante" (WISNIK, José Miguel. O som e o sentido: uma outra história das músicas. São Paulo: Companhia das Letras, 1989 , p. 44). Nas bases de rap, empregam-se, além de ruídos urbanos, sons produzidos por scratch, em que o DJ produz um som distorcido com a fricção da agulha no vinil, produzindo ruído e ritmo ao mesmo tempo. 
para alguns, suas opiniões e avaliações nesse sentido são consideradas conservadoras, ao assumir a perspectiva aristocrática, como sugere, por exemplo, o filósofo Ansell-Pearson. O autor considera que essa visão política de Nietzsche a respeito de uma "renovada cultura trá gica e aristocrática" se vê, entretanto, abalada pela própria noção da legitimidade da modernidade. Questiona-se em que medida seria possível uma disciplina política aristocrática sem produzir ressentimento. Sustenta, nesse sentido, que a própria genealogia da moral empreendida por Nietzsche torna discutível seu posicionamento subjacente às imagens de forte e fraco, de senhor $\mathrm{e}$ de escravo, ao supor que a moralidade é uma recusa à vida e que esta é fundamentalmente amoral, chegando a sustentar que "onde falta vontade de poder, há declínio"27. Segundo ele, a perspectiva histórica implícita em sua genealogia da moral abre caminho para a interpretação de que também a revolta dos escravos representa uma vontade de poder. Observa ainda que "a revolta dos escravos na moralidade não é apenas uma revolta contra a 'vida' mas antes uma revolta contra certa forma particular de vida, de opressão política e alienação religiosa..." ${ }^{28}$.

Mas a qual moralidade Nietzsche está se referindo ao associá-la à "recusa à vida", senão a moralidade socrático-platônica ou o "platonismo do povo" - o cristianismo?

A meu ver, embora as questões levantadas por Ansell-Pearson possam se colocar do ponto de vista histórico, não há como desvincular esta dimensão da perspectiva psicológica. Como se pode observar no Aforismo 23, de Além do bem e do mal, Nietzsche ${ }^{29}$ denuncia o aspecto moralizante que acompanhou a psicologia até então - quando, por exemplo, denuncia que a mesma até então não ousara "descer às produndezas", por ter ficado presa a "preconceitos e temores morais" e se propõe a construir uma psicologia movida por uma "morfologia e uma teoria da evolução da vontade de poder"30. Daí, sim, a psicologia se converterá no caminho para a resolução dos problemas fundamentais, segundo Nietzsche.

De acordo com Giacoia, na verdade, do ponto de vista histórico-social, Nietzsche teria se antecipado à crítica empreendida por T. W. Adorno e Max Horkheimer à crença emancipatória na Razão Ocidental

27 NIETZSCHE, Friedrich. O anticristo. (Aforismo 6) apud ANSELL-PEARSON, Keith. Nietzsche como pensador político: uma introdução. Rio de Janeiro: Jorge Zahar, 1997, p. 169 .

28 ANSELL-PEARSON, Keith. Nietzsche como pensador político: uma introdução, op. cit.

29 NIETZSCHE, Friedrich. Além do bem e do mal: prelúdio a uma filosofia do futuro, op. cit., p. 27.

zo Idem, Ibidem. 
Iluminista, que continua "cega e cruel, alienante e desumana" ${ }^{\text {. Sua }}$ menção ao espírito aristocrata se faz no sentido de buscar inspiração para pensar as condições de grandeza necessárias à elevação do Homem para além do Homem (rebanho). Mas há ainda o sentido psicológico, metafórico e espiritual: quando o sentido de escravidão é associado ao conflito entre as instâncias psíquicas, como condição de diferenciação e de opressão no interior do indivíduo. Por fim, leva-nos a crer que a história da cultura superior não se faz apartada da sublimação da crueldade ou, como salienta Giacoia, da história de sua "interiorização e espiritualização"32. Está se referindo ao que depois será objeto de extensa reflexão por parte de Freud, em $O$ mal-estar na civilização ${ }^{33}$ - ou seja, o sentimento de culpa que subjaz à cultura ocidental.

Ainda a propósito da letra do rap dos Racionais MC's, "Sou mais você", depreende-se que é preciso ser forte para enfrentar a "selva de pedra" da megalópole excludente, como se pode observar no seguinte trecho: "A premissa é inimiga da vitória, o fraco não tem espaço, e o covarde morre sem tentar... Cabeça, erguida, olhar sincero ... Tá com medo de quê?/ Faz o certo, faz a sua”, aconselha Mano Brown.

Eis a força da autodeterminação de que fala Nietzsche a propósito do "espírito livre". Mas, depois de quinhentos anos de opressão, como pode um afrodescendente exercitar sua autonomia? E libertar-se inclusive desta outra opressão que nos é incutida pela via da interiorização da crueldade, sob a forma de sentimento de culpa, o qual o cristianismo tratou de consolidar?

Nietzsche, ao defender o descentramento da razão e da consciência, antecipou não apenas as descobertas do inconsciente como ofereceu as bases para se pensar outra ordem de retorno do reprimido preconizado pela psicanálise freudiana - as culturas e subjetividades recalcadas pelas representações do monoculturalismo ocidental. É preciso observar que a vontade de poder defendida por Nietzsche e particularmente, o seu desdobramento no perspectivismo - em que combina as dimensões histórica e psicológica, de onde derivariam diferentes morais - "rompem-se os grilhões que prendiam a consciência filosófica ao 'tu deves' incondicional vigente na moral cristã”, ao mesmo tempo em que denuncia a "cumplicidade entre a moral cristã e o projeto político da modernidade" 34 . Ora, contrariamente à exigência de obediência e de

31 GIACOIA JÚNIOR, Oswaldo. Nietzsche \& Para além de bem e mal, op. cit., p. 61.

32 Idem, Ibidem, p. 62.

33 FREUD, Sigmund. El malestar em la cultura. Trad. José L. Etcheverry. In: Obras completas Sigmund Freud(1927-1931). Buenos Aires: Amorrortu, 2001, v. 21, p. 57-140.

34 GIACOIA JÚNIOR, Oswaldo. Nietzsche \& Para além de bem e mal, op. cit., p. 47. 
coerção adscritas à moralidade, Nietzsche propõe uma consciência filosófica "livre e libertadora", da qual me parecem ter-se imbuído rappers, como os Racionais MC's e Z'África Brasil, cujos chamados à humanidade não se fazem apartados de "atos supremos de autoexame", como salientara Ansell-Pearson propósito do projeto político de Nietzsche. Este autor diz o seguinte a esse respeito: "Seu método de reflexão política dirigese não exatamente aos indivíduos, mas à humanidade. Sua exigência de uma reavaliação de todos os valores requer que os seres humanos realizem atos de supremo autoexame" ${ }^{\text {. }}$. E o faz a partir da experiência do nada (nihil, das Nichts), sendo este o desafio proposto por Nietzsche, segundo o autor, para repensar os limites impostos pela crise da modernidade. Pergunta-se, nesse sentido:

Como se pode resistir ao niilismo? Como pode ser suportado? Pode ser superado, ou devemos nos submeter a ele? Talvez o novo possa recomeçar quando o homem se deslocar do centro e aguardarmos, com o devido cuidado e uma atenta responsabilidade, a chegada da época do pós-homem. Quem transmitirá esse destino à humanidade? A própria humanidade ${ }^{36}$

Se atentarmos para a ambiguidade sugerida pela verso do rap, "Sou + você", dos Racionais MC's, mencionado anteriormente: "Eu tenho fé e amor no século XXI, onde as conquistas, científica, espaciais, medicinais e a confraternização dos homens e a humildade de um rei serão as armas da vitória para a paz universal", não há aí o exercício de construção de um novo projeto para a humanidade? E assim o fazem no mesmo momento em que derrubam toda crença possível na autossuperação desta última.

Para se compreender esta e outras questões foi-nos fundamental a discussão trazida por Carril ${ }^{37}$, muito atual, aliás, a respeito da territoria$\operatorname{lidade}^{38}$, concebida pela autora como a relação de forças e de lutas sociais

35 ANSELL-PEARSON, Keith. Nietzsche como pensador político: uma introdução, op. cit., p. 170.

36 Idem, Ibidem, p. 170-171.

37 CARRIL, L. Quilombo, favela e periferia: a longa busca de cidadania. São Paulo: Annablume/Fapesp, 2006.

38 A socióloga americana, Saskia Sassen, da Universidade de Colúmbia e autora do livro Sociologia da globalização (Porto Alegre: Artmed, 2010), em reportagem recente no jornal O Estado de S. Paulo (caderno "Aliás", 25 dez. 2011, p. J3.), referindo-se aos protestos na praça Tahrir, aos indignados espalhados pela Europa e ao Occupy Wall Street (OWS), considera que em todos esses movimentos estaria presente a noção de território, concebido como "condição complexa na qual se insere a lógica do poder e 
sobre o espaço urbano, sobretudo quando analisa o reaparecimento da ideia de quilombo em letras de $r^{3} p^{39}$.

\section{O Quilombo no rap: por uma territorialidade urbana libertária}

Carril esclarece tratar-se - como fora no passado para os escravos que lutaram por sua liberdade, reapropriando-se da memória social e sentido de comunidade perdidos com a diáspora africana nas Américas - de uma nova luta pela reparação de um território perdido - no sentido social e histórico, eu diria, inspirada pelas leituras de Nietzsche e Honneth, também psicológica e moral - opondo-se, assim, ao confinamento territorial, ao banimento da vida pública e do mercado de trabalho e à humilhação social decorrente, a que estão sujeitos, ainda hoje, os jovens pobres urbanos, em sua grande maioria, afrodescendentes.

Inspirando-nos em algumas letras de rap que recorriam à imagem de Quilombo em seu aspecto libertário e restituidor de uma territorialidade perdida, assim como na experiência de autores americanos que já vinham promovendo uma educação crítica baseada no hip hop, nossa ideia era a de que justamente pudéssemos contribuir para despertar nos jovens, assim como nos educadores, a consciência de que não se tratava de criar um mundo ilusório, sem dores e marcas de um processo histórico que culmina, na atualidade, com a lógica excludente da globalização. Mas, pelo contrário, que justamente em face desta realidade e das tendências à pulverização de ideias e conceitos pouco adensados, para garantir privilégios há muito tempo estabelecidos, pretendíamos construir com os jovens um conhecimento culturalmente relevante e compromissado com sua emancipação.

Acresce-se a esta reflexão, todo um debate feito por alguns dos autores americanos pesquisados por nós - como Duncan-Andrade e

da reivindicação". Ressalta ainda que a prática disseminada por estes movimentos de ocupar o espaço público é uma forma de fazer história e de reelaborar e combater a lógica do poder antidemocrática incrustrada em dado território.

39 Como se pode verificar no refrão da letra, "Antigamente Quilombo, hoje periferia", do grupo de rappers Z'África Brasil, analisada pela autora: "A que sentidos flores prometeram um mundo novo?/ Favela viela morro tem de tudo um pouco/ Tentaram alterar o DNA da maioria/ Rei Zumbi! Antigamente Quilombo hoje periferia?/ Levante as caravelas aqui não daremos tréguas não, não/Então que venha a guerra/ Zulu Z'África Zumbi aqui não daremos tréguas não, não/Então que venha a guerra". 
Morrel $^{40}$ e Osumaré ${ }^{41}$, dentre outros -, que têm se debruçado sobre o hip hop como fenômeno da cultura urbana, com forte enraizamento na tradição afro-americana da produção musical e como estratégia fundamental de promoção de cultura e educação na periferia dos grandes centros urbanos.

Daí a importância dos estudos de Axel Honneth ${ }^{42}$ a respeito da luta pelo reconhecimento das populações historicamente prejudicadas como condição do avanço moral da sociedade.

Que efeitos de "ecos" discordantes produzem as teses da "luta pelo reconhecimento" sobre uma "leitura nietzschiana" do rap

Embora reconheçamos nas proposições crítico-destrutivas de Nietzsche a propósito da moralidade (socrático-platônica-cristã), subjacente ao projeto político de modernidade, um instrumento fundamental de leitura do mundo contemporâneo e de manifestações culturais como o rap e o movimento hip hop, e nos distanciarmos das interpretações que identificam em Nietzsche uma justificativa do ideário aristocrata e do próprio regime de escravidão, não há como negar que seria preciso discutir com maior cuidado suas críticas a toda e qualquer política de igualdade. Ansell-Pearson observa, inspirando-se no livro de Michael Walzer, Spheres of Justice, a defense of pluralism and Equality (1983), que:

As políticas igualitárias são uma resposta prática à experiência de subordinação e exclusão, não a expressão de uma inveja ou ressentimento natural. Como Walzer enfatiza, o que dá origem à política igualitária não é o fato de não haver rico e pobre, mas o de que o rico "tira a camisa ao pobre" e impõe-lhe a pobreza pela força e dominação. ${ }^{43}$

A luta pelo reconhecimento dessas populações que foram objeto de extensa e longa dominação parece-nos central para se compreender

40 DUNCAN-ANDRADE, J. M. R.; MORREL, E. Possibilities for Moving from Theory to Practice in Urban Schools. Nova Iorque: Peter Lang, 2008.

41 OSUMARÉ, Halifu. The Africanist Aesthetic in Global Hip Hop: Power Moves. Nova Iorque: Palgrave Macmillan, 2007.

42 HONNETH, Axel. Luta por reconhecimento: a gramática moral dos conflitos sociais, op. cit.

43 ANSELL-PEARSON, Keith. Nietzsche como pensador politico: uma introdução, op. cit., nota 2, p. 176 . 
os conflitos sociais contemporâneos, como pretende Axel Honneth ${ }^{44}$. Suas ideias podem até mesmo fazer avançar o pensamento de Nietzsche sobre a moralidade, porém num sentido ligeiramente discordante. Embora se possa reconhecer em Nietzsche uma crítica contundente aos falsos princípios igualitários propalados pela democracia burguesa e que sua preocupação era no sentido de buscar o que havia de mais nobre no ser humano - "a humildade de um rei", como dizem os rappers - para se repensar a Humanidade, é preciso analisar no campo da luta social como é possível reduzir as desigualdades sócio-políticas para que realmente se possam alcançar esses anseios. Ou mais especificamente, numa leitura habermasiana, é preciso forçar a argumentação quando as classes dominantes não querem ouvir as classes dominadas. Com isso, impõese momentaneamente uma igualdade de poder, o que não se faz sem o confronto, a luta e a guerra se for preciso, como têm dito os rappers em suas músicas de protesto e conscientização da juventude periférica.

Axel Honneth, que foi assistente de Habermas e depois o substituiu na Universidade e na direção do Instituto de Pesquisa Social, considera que Habermas teria negligenciado alguns aspectos que lhe pareceram essenciais. Supõe que a teoria social crítica deva ser ancorada "no processo de construção social da identidade", cuja gramática envolveria necessariamente a "luta pela construção da identidade", entendida como "luta pelo reconhecimento". Mas, ao contrário de Habermas, supõe a centralidade do conflito, que passa a se constituir em "uma crítica tanto à distinção habermasiana entre sistema e mundo da vida, como a uma suposta lógica do acordo, do entendimento e da cooperação que caracterizaria de saída o domínio do mundo da vida" ${ }^{\text {"5 }}$.

Nessa mesma direção, acredito que justamente o movimento hip hop ganha corpo e estatuto político porque tem procurado associar à reconstrução da identidade do jovem pobre e negro a luta por reconhecimento pessoal e social. Já a luta pelo reconhecimento no campo jurídico tem sido objeto de ação política do movimento negro.

44 HONNETH, Axel. Luta por reconhecimento: a gramática moral dos conflitos sociais, op. cit.

45 Idem, Ibidem, p. 11. 


\section{Uma educação baseada no hip hop e a luta pelo reconhecimento}

Nossa ideia a propósito de uma educação inspirada no hip hop tema de nossa pesquisa ${ }^{46}$, enquanto expressão do que tem sido denominado de "pedagogia crítica"47 "culturalmente relevante"48 articulando-a com o debate sobre o multiculturalismo e a educação contemporânea voltada para a diversidade, é promover o que o filósofo contemporâneo, Axel Honneth ${ }^{49}$ - que faz dialogar os princípios da teoria crítica com a psicanálise - chamou de "progresso moral na dimensão do reconhecimento".

É nesse contexto que me parece atual o debate em torno da dimensão moral dos conflitos sociais na luta pelo reconhecimento, sustentada por Honneth, do qual me parece fundamental que a psicanálise se aproprie, sobretudo se pensarmos na clínica extensa tal como pensada por Herrmann (1991), que propõe que a psicanálise atue muito mais como método de ruptura de campos. No caso, a ruptura que me parece necessária é uma ruptura com um pensamento e cultura eurocêntricos, incapazes de abarcar a diversidade cultural que nos constitui e de fazer avançar um projeto emancipatório, que embora possível, vê-se bloqueado pela estrutura social vigente no Brasil, bastante desigual e racista. Um racismo à brasileira que se viu encoberto por uma política do branqueamento implantada no país desde a escravidão, que associava a liberdade ao mundo branco, e depois se viu incrementada pela política da imigração europeia, que não apenas alimentou o mito da democracia racial como foi responsável pela não explicitação dos conflitos. Com todas as consequências nefastas que se estendem até hoje, fazem com que as pessoas se vejam impelidas a negociar suas identidades, como bem salientou Lilia Schwarcz no artigo: "Nem preto, nem branco, muito pelo contrário: cor e raça na intimidade" ${ }^{50}$. Foi preciso que o movimento

46 Sob o título: Rappers, os novos mensageiros urbanos na periferia de São Paulo: a contestação estético-musical que emancipa e educa, op. cit.

47 Henry Giroux, em íntima colaboração com Paulo Freire, tomando como referência os estudos frankfurtianos, empenhou-se em construir as bases de uma teoria crítica da pedagogia, que foram expostas no livro de sua autoria: GIROUX, Henry. Pedagogia radical: subsídios. São Paulo: Cortez, 1983.

48 Inspiramo-nos particularmente nas ideias de DUNCAN-ANDRADE, Jeffrey M. R. ; MORREL, Ernest. The Art of Critical Pedagogy. Nova Iorque: Peter Lang, 2008.

49 HONNETH, Axel. Luta por reconhecimento: a gramática moral dos conflitos sociais, op. cit, p. 265.

5o SCHWARCZ, Lilia Moritz. Nem preto, nem branco, muito pelo contrário: cor e raça na intimidade. In: (Org.). História da vida privada no Brasil. São Paulo: Companhia das Letras, 1998. 
negro no Brasil ganhasse força nos anos 1980/1990, conforme salientou Iray Carone em conferência recentemente proferida, para que o Brasil admitisse que é racista. Ela diz o seguinte:

Vejam bem: se hoje temos uma lei que condena a discriminação racial - a Lei Caó - que faz parte inclusive da Constituição de 1988 - foi graças ao movimento negro e a suas lideranças. Se hoje temos uma discussão implantada na sociedade pelas políticas de ação afirmativa - que ainda estão em curso - foi graças ao movimento negro e a suas lideranças a partir da década de 90 . Se hoje admitimos que o Brasil não é uma democracia racial e que existe racismo no chamado paraíso racial, é porque o movimento negro se fez ouvir. Se hoje nos interessamos pela história da África e da sua cultura, a ser implantada nos currículos escolares, é porque o movimento negro vem alterando a cultura social e política do país - vencendo o nosso incrível atraso. ${ }^{51}$

Honneth defende, por fim, fazendo avançar as hipóteses do jovem Hegel e de George Mead, que

são as três formas de reconhecimento do amor, do direito e da estima que criam primeiramente, tomadas em conjunto, as condições sociais sob as quais os sujeitos humanos podem chegar a uma atitude positiva para com eles mesmos; pois só graças à aquisição cumulativa de autoconfiança, autorrespeito e autoestima, como garante sucessivamente a experiência das três formas de reconhecimento, uma pessoa é capaz de se conceber de modo irrestrito como um ser autônomo e individuado e de se identificar com seus objetivos e seus desejos. ${ }^{52}$

E quando essas condições não se verificam? Quais as consequências de mais de três séculos de escravidão, como sustentou Carone ${ }^{53}$, com toda a barbárie cometida contra as populações de afrodescendentes e o posterior banimento dos mesmos do mercado de trabalho, para gerações e gerações de famílias negras neste país? Que relação tem tudo isso com

51 Refiro-me à conferência "O movimento negro nos anos 9o", proferida pela Profa. Iray Carone, In: Colóquio Internacional Culturas Jovens Afro Brasil América: encontros e desencontros, FEUSP, abril de 2012.

$5^{2}$ HONNETH, Axel. Luta por reconhecimento: a gramática moral dos conflitos sociais, op. cit., p. 266 - o grifo é nosso.

53 CARONE, Iray. "O movimento negro nos anos 9o", op. cit. 
as mortes de jovens negros e pobres moradores da periferia de cidades como São Paulo?

Como disseram os jovens, com quem desenvolvemos oficinas de rap e letramento:

"Respeitando a comunidade"

Vamos respeitar a comunidade

Tem muita violência nessa cidade

Tem ódio, rancor e no peito muita dor.

Eu levo o sofrimento

Porque na quebrada não tem jeito

Se fechar o olho, RAM!

Perde o respeito

O muleque levanta a cabeça

Porque na favela

Tem muita tristeza

Sai da ilusão e cai no mundão.

Bota o sorriso no rosto

E vem cantar essa canção. ${ }^{54}$

Como dizem os Racionais MC's: "Nunca foi fácil, junte os seus pedaços e desce pra arena”.

Axel Honneth, partindo do pressuposto de que a integridade do ser humano se deve em grande parte a padrões de reconhecimento nos três níveis acima descritos, categorias morais como de ofensa e sentimento de rebaixamento surgem frequentemente quando as pessoas são submetidas a formas de "reconhecimento recusado". Nesse sentido, as lutas contra os sentimentos de injustiça e de desrespeito podem ser interpretados, não apenas como motivadoras de lutas sociais, mas também exercendo o papel moral que lhes competem nos desdobramentos das relações de reconhecimento. Esta é uma dimensão até então pouco explorada, ou seja, que a posição assumida pelas lutas, conflitos e reivindicações só se explicita quando se torna apreensível o papel

54 Como parte da pesquisa de políticas públicas (op. cit., 2011 - 2013), desenvolvemos oficinas com o rap, dentre elas, $O$ rap como possibilidade de letramento: a construção da identidade e a reflexão sobre a constituição das subjetividades dos jovens da periferia de São Paulo, que foi coordenada pela orientanda de mestrado, Ana Claudia Florindo (FEUSP). 
que "desempenham para o estabelecimento de um progresso moral na dimensão do reconhecimento" ${ }^{55}$.

Nesse sentido, talvez tenha faltado a Nietzsche a percepção de que o "reconhecimento recusado" - nos planos moral, jurídico e social - a que foram sujeitos particularmente nossos afrodescendentes, e consequentemente, o "ressentimento" que isso possa acarretar, só poderá ser superado para além de uma postura e uma moral nobre, tal como assumidas pelos rappers, quando efetivamente os diversos níveis de reconhecimento, apontados pelo autor, forem realidade efetiva em nossa sociedade.

Por fim, Honneth salienta como correspondem aos três padrões de reconhecimento quando recusados, três níveis de desrespeito, que, uma vez ancorados na experiência afetiva dos seres humanos, podem ser o impulso para a resistência social e para o conflito:

$1^{\circ}$ tipo de desrespeito: quando toca $a$ integridade corporal de uma pessoa, infligindo-lhe maus-tratos, como ocorre sob o regime da escravidão, violação e tortura. É o nível que conduz ao nível mais elementar de rebaixamento pessoal, provocando um grau de humilhação profunda (não se pode esquecer que se rompe o eu-corpóreo, o eu-pele, invólucro do eu), além de colocar a pessoa à mercê da vontade do outro, sem nenhuma proteção, chegando a conduzir à perda do senso de realidade (desrealização de si como ser dotado de vontade), destruindo a confiança em si mesmo ${ }^{56}$;

$2^{\circ}$ tipo de desrespeito: desrespeito pessoal e moral por se ver "estruturalmente excluído" da posse de direitos em pé de igualdade com outros grupos sociais. Isto implica não somente em "violenta limitação da autonomia pessoal", como também desencadeia o "sentimento de não possuir o status de um parceiro da interação com igual valor, moralmente em pé de igualdade" ${ }^{57}$.

$3^{\circ}$ tipo de desrespeito: referir-se negativamente ao valor social de indivíduos e grupos, de "depreciação de modos de vida individuais ou coletivos". Ora se o grau de estima social depende das possibilidades de autorrealização no universo de sua tradição cultural e se a sociedade degrada as condições de vida ou desvaloriza crenças

55 HONNETH, Axel. Luta por reconhecimento: a gramática moral dos conflitos sociais, op. cit, p. 265.

56 Idem, Ibidem, p. 215 .

57 Idem, Ibidem, p. 216. 
e valores, ela retira dos indivíduos "toda possibilidade de atribuir um valor social às suas próprias capacidades" 58 .

Chega a atribuir a cada uma dessas formas de desrespeito três níveis de sequelas psíquicas e sociais: na primeira, a morte psíquica, como no caso da tortura; no caso da escravidão, associada à primeira, pode levar ainda à morte social; e o terceiro tipo de desrespeito, à degradação cultural, a vexação ou humilhação social. Com a experiência de rebaixamento e humilhação social, a identidade do sujeito se vê ameaçada, cujas reações emocionais negativas acabam expressando-se muitas vezes no sentimento de vergonha social, que tem abalado fortemente a saúde psíquica das populações prejudicadas historicamente.

O que daria sustentação à integridade psíquica dessas populações? Justamente a "garantia social de relações de reconhecimento capazes de proteger os sujeitos do sofrimento de desrespeito da maneira mais ampla"59. Tais teses nos sugerem como a luta política hoje passa necessariamente pela luta pelo reconhecimento da identidade, social, moral e psíquica.

Analisemos o que propõem os jovens noutro trecho da composição coletiva de rap citada acima, inspirados em uma leitura crítica de mundo, quando instigados por Ana Cláudia Florindo, que coordenou a oficina de rap e letramento:

"Respeitando a comunidade"

Olha pra frente e cai na real, Porque na Zona Sul é mais legal

O bom não é ruim, e o ruim não é bom.

Por que na quebrada é tudo sangue bom

Muleque, presta atenção

Preste atenção, Aqui é o Capão.

Vô mandar um papo reto

Essa é a missão

Sair por aí fazendo união

Tá ligado meu irmão?

(letra de Marco Antonio, Valéria e Geyse)

58 Idem, Ibidem, p. 217.

59 Idem, Ibidem, p. 219. 
O pleno engajamento dos alunos, mesmo daqueles com maiores dificuldades de leitura e escrita, combinado com o modo como a pesquisadora foi promovendo junto a eles o aperfeiçoamento da escrita da língua portuguesa, sem desmerecer o emprego da linguagem oral e as origens multiétnicas de nossa língua, nos fez lembrar justamente das observações do filósofo francês, Christian Béthune ${ }^{60}$.

De acordo com o autor, além de uma forma lúdica de lidar com os ritmos musicais, o estilo rap inventa palavras, em um jogo de vaivém, ao mesmo tempo em que promove uma verdadeira inversão recompondo uma nova relação entre o campo da oralidade e da escrita, uma vez que insiste em fazer entrar para o interior da linguagem escrita a linguagem oral proscrita dos bancos escolares.

Além desse recurso de inversão da lógica no campo da escrita, para evitar os três níveis de desrespeito pessoal, moral e social, como sugere Axel Honneth, é preciso reverter também os valores que sustentam a moralidade preconceituosa vigente, que garante e sustenta a exclusão dos jovens pobres e negros, quando não, justifica o seu extermínio: "O bom não é ruim, e o ruim não é bom”, como nos ensinam os jovens. Porque ao contrário do que se veicula na sociedade, "na quebrada é tudo sangue bom".

E assim o letramento e o conhecimento têm avançado em nossas oficinas com jovens a partir do momento em que suas dores têm sido elaboradas por esses "curadores feridos": na capoeira ${ }^{61}$, com suas músicas que lembram a humilhação e os maus-tratos a que foram submetidos os escravos, revelando um luto impossível; os rappers, que convertem a humilhação da periferia, no confronto com a polícia e a sociedade discriminatória, em força e união: "Essa é a missão/ Sair por aí fazendo união/ Tá ligado meu irmão?”, dizem os jovens em sua composição de rap.

6o BÉTHUNE, Christian. D’une Expression mineure: ce que le rap fait à la culture dominante. In: COLÓQUIO INTERNACIONAL CULTURAS JOVENS AFRO BRASIL AMÉRICA: encontros e desencontros, FEUSP, abril de 2012.

61 Como se pode depreender de uma letra comumente entoada nas rodas de capoeira, "Sou guerreiro Quilombo, quilombola", de autoria de Mestre Barrão: "Eu sou Negro dos Bantos de Angola/ Negro nagô/ Fomos trazidos pro Brasil/ Minha família separou/ Minha mãe foi vendida/ Pra fazenda de um senhor/ O meu pai morreu no tronco/ No chicote do feitor/ O meu irmão não tem a orelha/ Porque o feitor arrancou/ Na mente trago tristeza/ E no corpo muita dor/ Mas olha um dia/ Pro quilombo eu fugi/ Com muita luta e muita garra/ Me tornei um guerreiro de Zumbi”. 
De outro lado, outra pesquisadora de nossa equipe, Raquel Martins $^{62}$, ao promover junto aos jovens desde o estranhamento sonoro à improvisação e à elaboração de ideias musicais autônomas, "procurou estimular entre eles o questionamento diante das verdades que lhe são entregues prontas tirando-lhes o benefício da dúvida, a começar pelo questionamento dos valores atribuídos às músicas que mais gostavam" ${ }^{63}$ Procurou expandir esse olhar crítico para outros valores moralizantes e alienantes arraigados nos jovens que, segundo Nietzsche, referir-se-iam a uma "vontade de verdade" ${ }^{64}$. Provocar através da música essa ruptura com a comodidade que obscurece o pensamento crítico tem sido um grande desafio para a pesquisadora, visto que estimula os alunos a "reconhecer a inverdade como condição de vida: isso significa sem dúvida, enfrentar de maneira perigosa os habituais sentimentos de valor, além do bem e do mal"65.

Neste segundo ano da pesquisa, a pesquisadora concentrou seus esforços no desenvolvimento da consciência crítica, procurando trabalhar com a formação intelectual e da subjetividade dos alunos por meio das experiências musicais que conduzissem à reflexão. A estética do rap presente na composição musical e na interpretação das letras é reconhecida como estratégia fundamental de afirmação do espírito contestatório que se pretendia fomentar no adolescente, para que este pudesse fazer face ao conformismo perante a realidade de exclusão em que tem sido colocado.

\section{A título de conclusão}

O desenvolvimento da pesquisa Rappers, os novos mensageiros urbanos na periferia de São Paulo: a contestação estético-musical que emancipa e educa (2011 - 2013) na ONG Casa do Zezinho, durante dois anos, foi de vital importância para realizarmos esta análise e propor a continuidade

62 Como parte da mesma pesquisa de políticas públicas (op. cit., 2011 - 2013), desenvolvemos, ainda, outra oficina: Improvisação rítmica e composição musical do rap com instrumentos de percussão afro-indigenas, que foi coordenada pela mestranda, Raquel Martins (FEUSP).

63 MARTINS, Raquel. apud AMARAL, M. (coord.). Relatório Científico Final do Projeto de Pesquisa Rappers, os novos mensageiros urbanos na periferia de São Paulo: a contestação estético-musical que emancipa e educa, Fapesp, 2012, p. 353)

64. NIETZSCHE, Friedrich. Além do bem e do mal. op cit., p.og.

65 Idem, Ibidem, p.11. 
do projeto, em 2013, junto à Escola de Aplicação da Universidade de São Paulo, inserindo-o no Projeto Negritude existente na referida escola.

Foram muitas as respostas criativas e inteligentes dos jovens que se apropriaram das oficinas e puderam trabalhar com o rap, articulando-o a suas realidades, produzindo letras, danças, textos e bases de rap com instrumentos afro-indígenas. Foi se construindo uma leitura da cidade de São Paulo a partir da história do negro e com isso, apropriaram-se de uma territorialidade perdida e de uma história a ser recontada em novas bases.

Enfim, trata-se da reparação de uma territorialidade e de uma identidade perdidas, cujo enfrentamento é importante não apenas para aqueles que se sentem excluídos, mas que pode contribuir para o avanço moral da sociedade brasileira. A pergunta acerca do papel da psicanálise será feita aqui a propósito da educação. Em que medida poderá contribuir para os três modos de reconhecimento apontados por Axel Honneth? Para o avanço da autoconfianca no campo amoroso, do autorrespeito, oriundo das formas de reconhecimento dos direitos no campo jurídico e de autoestima, que dependerá do avanço da solidariedade e a da estima social em relação aos grupos historicamente prejudicados. Para tanto é preciso que não mais se tolerem formas de desrespeito que impliquem em: maus-tratos e violação da pessoa; a privação de direitos e a exclusão de grupos sociais; a degradação e a ofensa a grupos e culturas, presentes em toda forma de discriminação.

A ideia de construir uma educação em novas bases, inspirada no hip hop e por todas essas leituras que temos feito, é de combinar estudos sobre a diáspora africana colonial e pós-colonial e a história dos negros no Brasil, com os estudos sobre a presença de nossa ancestralidade africana na música, nas práticas do improviso, do canto em roda, na capoeira e de como todas essas manifestações culturais são recriadas pelos jovens do mundo inteiro por meio das chamadas culturas urbanas de rua - envolvendo desde o rap, as batalhas de rima e de break, a prosódia, bem como as batidas do rap e do funk, e assim por diante. E desse modo, recriam algo fundamental no mundo contemporâneo - caracterizado por Žižek ${ }^{66}$, como worldless (sem mundo, sem lugar) - sobretudo para os jovens pobres e negros - uma identidade etnorracial, territorial e psíquica.

Revisitar Nietzsche, cujo pensamento é considerado o divisor de águas que distingue o pensamento moderno e o pós-moderno, tem sido essencial nesse sentido: em particular, suas ideias críticas a respeito dos estabelecimentos de ensino e a cultura a ser transmitida às novas

66 ŽIŽEK, Slavoj. Violence. Nova Iorque: Picador, 2008. 
gerações ${ }^{67}$; o empenho do desejo e das "afecções fortes" eliciadas pela filosofia dionisíaca que exerceram um papel fundamental em sua genealogia da moral, a partir das quais propôs a transvaloração dos valores vigentes na modernidade ${ }^{68}$. Tanto o aspecto afirmativo que, segundo Deleuze ${ }^{69}$, estaria presente na "visão dionisíaca de mundo", sustentada por Nietzsche $^{70}$, quanto a ideia de "estética extrema" ${ }^{71}$, salientada por Heidegger ${ }^{72}$, pareceram-me essenciais para uma interpretação conceitual afinada com o movimento histórico de nosso objeto, ou seja, as culturas juvenis contemporâneas por nós estudadas, a saber: hip hop, rap, break e funk ${ }^{73}$. A nosso ver, estes movimentos da cultura popular urbana constituem-se em manifestações estéticas de vanguarda. Encontrando-se marcados por elementos estéticos específicos ${ }^{74}$, pautados, por sua vez, por forte hibridismo cultural, em particular os elementos do movimento hip hop - rap, break e graffiti - embora inseridos no fenômeno da mundialização da

67 NIETZSCHE, Friedrich. Sobre o futuro de nossos estabelecimentos de ensino (1872). In: . Escritos sobre educação. Trad. Noéli Correia de Melo Sobrinho. Rio de Janeiro: PUC-RJ/Loyola, 2004, p. 41-137.

68 Destacamos, aqui, o caráter afirmativo de sua filosofia, inspirando-nos na concepção trágica do homem grego (NIETZSCHE, Friedrich. O nascimento da tragédia no espírito da música (1872). In: Os pensadores. Obras Incompletas/F. Nietzsche. Seleção de textos de Gérard Lébrun. $3^{\mathrm{a}}$ ed. São Paulo: Abril Cultural, 1983, p. 5-28.), a partir da qual pretendeu construir uma nova genealogia dos valores, ou seja, o valor dos valores, o que abriria a experiência humana a uma pluralidade de sentidos (NIETZSCHE, Friedrich. Genealogia da moral: uma polêmica (1887). São Paulo: Companhia das Letras, 2006).

69 Deleuze, G. Nietzsche e a filosofia. Porto: Portugal, [s/d].

70 NIETZSCHE, Friedrich. A visão dionisíaca do mundo (1870). In: A visão dionisíaca do mundo e outros textos de juventude. Trad. Marcos Sinésio P. Fernandes e Maria Cristina dos Santos Souza. São Paulo: Martins Fontes, 2005, p. 3-44.

71 Heidegger (Nietzsche ..., op. cit. ), em suas preleções sobre Nietzsche, sustenta que o autor, a partir de $O$ crepúsculo dos ídolos, caminha menos no sentido de uma metafísica do artista (cf. MACHADO, Roberto. Nietzche e a verdade. Rio de Janeiro; Graal/Paz e Terra, 2002) e mais no sentido de uma "estética extrema", a partir da qual se evidenciou, para nós, a potencialidade crítica e afirmativa da estética étnico-juvenil do hip hop e do funk, no âmbito escolar.

HEIDEGGER, M. Nietzsche, op. cit.

73 São ideias que desenvolvo no artigo: AMARAL, Mônica do. A estética transgressora do rap e do funk: em direção à reversão dialética da educação pública nas metrópoles brasileiras. In: .; SOUZA, Maria Cecília C. C. de. Educação pública nas metrópoles brasileiras. São Paulo: Paco Editorial/Edusp, 2011.

74. Uma ideia muito próxima da que é defendida por Rodrigo Duarte em seu artigo Sobre o constructo estético-social (Revista Sofia, Ufes, v. XI, n. 17 e 18, p. 239-263, 2007.), onde o autor sustenta ter encontrado no rap uma forma de manifestação estética de outra ordem, cuja negatividade (formal e não apenas de conteúdo, a qual Adorno salienta ser característica da estética negativa da nova música) encontra-se marcada por elementos estéticos específicos: o break, um estilo de dança de rua; o rap, acompanhado de DJ e MC; o grafite, uma forma de expressão plástica. 
cultura, tendem a negá-lo em seus aspectos reificadores ao assumir uma atitude política de contestação (paradoxalmente, por meio de uma estética afirmativa) a todo tipo de discriminação e de exclusão social.

De outro lado, a leitura de Axel Honneth me fez pensar como o conhecimento da psicanálise, esta compreendida, conforme Herrmann ${ }^{75}$, como método de ruptura de campo, pode contribuir para o avanço moral da sociedade brasileira. E desse modo, contribuir para uma educação voltada à emancipação. Tenho me proposto a pensar em que medida poderá contribuir para os três modos de reconhecimento apontados pelo autor: para o avanço da autoconfiança no campo da construção da subjetividade; do autorrespeito, oriundo das formas de reconhecimento dos direitos no campo jurídico e da autoestima, que dependerá do avanço da solidariedade e a da estima social em relação aos grupos historicamente prejudicados.

Para tanto é preciso que não mais se tolerem formas de desrespeito que impliquem em: maus-tratos e violação da pessoa; a privação de direitos e a exclusão de grupos sociais; a degradação e a ofensa a grupos e culturas, presentes em toda forma de discriminação.

\section{Sobre a autora}

\section{Mônica G. T. do Amaral}

Professora associada do departamento de Filosofia da Educação e Ciências da Educação e docente do Programa de Pós-graduação em Educação da Faculdade de Educação da Universidade de São Paulo (USP, São Paulo, SP, Brasil).

E-mail: monicagta@hotmail.com

As reflexões apresentadas no artigo tomaram como base a pesquisa do Programa de Políticas Públicas, financiada pela Fapesp, coordenada pela autora, sob o título: Rappers, os novos mensageiros urbanos na periferia de São Paulo: a contestação estético-musical que emancipa e educa, em parceria da Feusp com a ONG Casa do Zezinho, Capão Redondo (Processo: 2010/52002-9). Este artigo é um desenvolvimento de uma conferência apresentada na mesa-redonda: "Psicanálise e Universidade", no $29^{\circ}$ Congresso Latino Americano de Psicanálise - Fepal, out. 2012.

75 Herrmann, Fábio. Andaimes do real: o método da psicanálise. São Paulo: Brasiliense, 1991 . 
